\title{
Prediction of adult height from height, bone age, and occurrence of menarche, at ages 4 to 16 with allowance for midparent height
}

\author{
J. M. TANNER, R. H. WHITEHOUSE, W. A. MARSHALL, and B. S. CARTER \\ From the Department of Growth and Development, Institute of Child Health, University of London
}

Tanner, J. M., Whitehouse, R. H., Marshall, W. A., and Carter, B. S. (1975). Archives of Disease in Childhood, 50, 14. Prediction of adult height from height, bone age, and occurrence of menarche, at ages 4 to 16 with allowance for midparent height. Multiple regression equations for predicting the adult height of boys and girls from height and bone age at ages 4 and upwards are presented. There is a separate equation for each half year of chronological age; and for pre- and postmenarcheal girls at ages 11 to 14 . These are based on longitudinal data from 116 boys and 95 girls of the Harpenden Growth Study and the London group of the International Children's Centre longitudinal study.

The bone age used is the revised version of the Tanner-Whitehouse stardards, omitting the score for carpal bones (RUS age, TW 2 system).

Boys aged 4 to 12 are predicted in $95 \%$ of instances to within $\pm 7 \mathrm{~cm}$ of true height, and at ages 13 and 14 to within $\pm 6 \mathrm{~cm}$. Girls aged 4 to 11 are predicted to within $\pm 6 \mathrm{~cm}$; premenarcheal girls aged 12 and 13 to within \pm 5 and $\pm 4 \mathrm{~cm}$, respectively; and postmenarcheal girls aged 12 and 13 to within \pm 4 and $\pm 3 \mathrm{~cm}$, respectively. Prediction can be somewhat improved by allowing for midparent height. One-third of the amount that midparent height differs from mean midparent height is added or subtracted.

An alternative system of equations which are based on initial classification by bone age rather than chronological age is given. These have about the same accuracy as the equations based on initial classification by chronological age, but allowance for bone age retardation is less. It is not clear which system is preferable.

The equations probably apply to girls complaining of tall stature and boys or girls complaining of shortness and needing reassurance as to normality. In clearly pathological children, such as those with endocrinopathies, they do not apply.

The adult height of a child who grows up under favourable environmental circumstances is to a large extent dependent on heredity. It may thus be predicted from the height of parents, though with a considerable degree of uncertainty which arises from the various possible combinations of the many genes controlling stature, as well as from epigenetic and environmental effects and their interaction (Fisher, 1918). Statistically speaking, each parent exerts an equal effect on the child's stature. The correlation between stature of adult offspring and the average of

Received 29 May 1974. the parents' heights ('midparent stature') is about $0 \cdot 75$, allowing for a tendency for taller men to marry taller women (assortative mating) and presuming that parents and children grow up under similarly favourable circumstances. A child's adult height can also be predicted from heights at earlier ages, with correlations at favourable ages of the order of 0.8 (Tanner et al., 1956). It takes time, however, for the child to come to resemble his parents, or himself as an adult; as a newborn his length reflects chiefly the conditions he experienced in his mother's uterus. Thus the full correlations with his parents' height or his own adult height are 
not established until about age 3 (Bayley, 1954; Tanner, Goldstein, and Whitehouse, 1970).

After this age prediction of adult height is possible from either of these relationships, with one proviso. Children differ greatly in the rate at which they pass through the various phases of growth; some have a rapid tempo of growth and attain adult status at a relatively early age; others have a slow tempo and finish growing relatively late. A child's height at any age reflects both how tall he will ultimately become and how far advanced he is towards that goal. If, therefore, an allowance is made for the child's degree of advancement or delay in growth, the correlations rise and the prediction becomes more accurate. This is particularly important within the age range at which the adolescent growth spurt occurs. At this time the correlations between present height and adult height drop to about 0.7 unless allowance is made for maturity (Tanner, 1962) because the rapid height change which constitutes the adolescent spurt occurs at very different ages in different children. The prediction can be improved if we know whether the spurt has occurred or not. In the clinical situation this is seldom known, and the only practical guide to maturity status is skeletal maturity or bone age, usually estimated from a hand-wrist $x$-ray. Though this is a very imperfect guide as to whether the most rapid phase of the adolescent growth has or has not occurred (Marshall, 1974), it does reflect well the general advancement or delay in height growth.

Bayley $(1946,1962)$ was the first to publish tables for predicting adult height from present height and bone age. These tables (Bayley and Pinneau, 1952), revised for use with the Greulich-Pyle (1959) skeletal maturity atlas, are those most frequently used at present. They have some disadvantages, however. They permit only a semi-quantitative allowance for bone age; there are three separate tables-one to be used when bone age is retarded by more than a year, the second if bone age is within a year of chronological age, and the third if bone age is more than a year advanced. Rather than using classical statistical techniques, each of the three tables gives per cent. of mature height attained at each age and the prediction is made from this. The age range covered begins only at 8 years.

Some years ago Tanner, Whitehouse, and Healy (1962) introduced a method for assigning skeletal maturity scores which we think has both theoretical and practical advantages over the Greulich-Pyle atlas. This is especially so in its second version (Tanner et al., 1975). We have, therefore, worked out predictions of adult height based upon it. We have used classical regression methods which permit a quantitative allowance for any degree of skeletal maturity, and present two sets of equations, one based on initial classifications by chronological age, the other on classification by bone age. We have also examined what features of the hand-wrist bone age contribute to diminishing the error of prediction, with the result that our equations are constructed using a bone age which excludes the carpals. The age range covered is 4.0 upwards. In girls we have incorporated knowledge of whether or not menarche has occurred, which improves the predictions.

\section{Subjects and methods}

The children studied were those members of the Harpenden Growth Study (Tanner, 1962; Tanner, Whitehouse, and Takaishi, 1966; Marshall and Tanner, 1969, 1970) and the International Children's Centre, London, Longitudinal Growth Study (Moore, Hindley, and Falkner, 1954) who had been followed until growth in height had virtually ceased. Our minimum criterion for this was an increment of less than $1 \mathrm{~cm}$ between two successive measurements taken a year or more apart. We are aware that some children, most of whom are boys, grow $1 \mathrm{~cm}$ or, rarely, $2 \mathrm{~cm}$ further (see Roche and Davila, 1972). However, most of our subjects were followed well beyond the minimum increment point, and their final height represents a value obtained by drawing a smooth curve through a succession of practically constant measurements. All subjects were healthy at all times of measurement.

Height. There were 79 boys and 56 girls from the Harpenden Growth Study and 37 boys and 39 girls from the International Children's Centre, London study. The Harpenden children entered the series at various ages from 3 to 10 ; they were measured 6-monthly till puberty, 3-monthly during puberty, and yearly thereafter till age 20 , then every 5 years. The ICC children entered the series at birth and were measured annually. All measurements on the Harpenden children were done by R.H.W.; on the ICC children the majority were done by J.M.T. or W.A.M. The technique used was that previously described (Marshall, 1974; Tanner et al., 1971) and adopted for the International Biological Programme (Weiner and Lourie, 1969). A Harpenden stadiometer was used, and gentle upward pressure applied under the mastoid processes to stretch the child to maximum stature. This procedure has been shown to minimize, though not entirely to eliminate, the decrease of stature which occurs during the day for postural reasons (Whitehouse, Tanner, and Healy, 1974). Midparent stature refers to the simple average of mother's and father's height measurements. Parents were measured by J.M.T.

Bone age. $X$-rays of the left hand and wrist were taken on each occasion of measurement and these were rated following the TW 2 system (Tanner et al., 1975). 
20 bones were rated, each on a 8- or 9-point scale, and three scores computed from a table giving values for each stage of each bone. The scores represent bone age as determined from (a) radius, ulna, metacarpals, and phalanges (RUS); (b) carpal bones; and (c) both (TW 2). Details of the scoring system and tables for converting scores into bone ages will be found in the book cited. All ratings were made either by R.H.W., W.A.M., or both. Comparison of the two raters showed that discrepancies greater than \pm 0.7 years occurred in only $10 \%$ of cases. Reference will also briefly be made to TW 1, the (arlier version of this system (Tanner et al., 1962).
Statistics. Standard multiple regression analysis was used, adult height being estimated from various combinations of other variables. Thus, typically, we have: Predicted adult height $=a$ present height $+b$ chronological age $+c$ RUS bone age $+d$, a constant. A worked example is given below, on page 22 . Equations were constructed both within given age bands and using age as an independent variable. The age bands were whole years, e.g. $8+$ (a terminology we use to indicate 8.00-8.99 years). Since most children were measured more frequently than once a year, most appear two or more times in each age group, giving the total subjectentry figures seen in Tables I and II.

TABLE I

Residual SDs and correlation coefficients in prediction of adult height from present height, age, and RUS bone age in boys

\begin{tabular}{|c|c|c|c|c|c|c|c|}
\hline \multirow{2}{*}{$\begin{array}{l}\text { Age } \\
(y r)\end{array}$} & \multirow{2}{*}{ No. } & \multicolumn{2}{|c|}{ Height } & \multicolumn{2}{|c|}{ Height + chronological age } & \multicolumn{2}{|c|}{$\begin{array}{c}\text { Height }+ \text { chronologica } \\
\text { age }+ \text { RUS bone age }\end{array}$} \\
\hline & & $\underset{(\mathrm{cm})}{\text { Residual }} \mathrm{SD}$ & $\mathbf{r}$ & $\underset{(\mathrm{cm})}{\text { Residual SD }}$ & $\mathbf{r}$ & $\underset{(\mathrm{cm})}{\text { Residual SD }}$ & $\mathbf{r}$ \\
\hline $\begin{array}{r}3+ \\
4+ \\
5+ \\
6+ \\
7+ \\
8+ \\
9+ \\
10+ \\
11+ \\
12+ \\
13+ \\
14+ \\
15+ \\
16+ \\
17+\end{array}$ & $\begin{array}{r}30 \\
58 \\
69 \\
105 \\
99 \\
105 \\
126 \\
131 \\
158 \\
234 \\
227 \\
210 \\
118 \\
113 \\
75\end{array}$ & $\begin{array}{l}6 \cdot 1 \\
4 \cdot 8 \\
4 \cdot 4 \\
4 \cdot 7 \\
4 \cdot 9 \\
4 \cdot 5 \\
4 \cdot 4 \\
4 \cdot 4 \\
4 \cdot 5 \\
5 \cdot 0 \\
5 \cdot 2 \\
4 \cdot 8 \\
4 \cdot 0 \\
2 \cdot 9 \\
1 \cdot 2\end{array}$ & $\begin{array}{l}0.63 \\
0.73 \\
0.76 \\
0.80 \\
0.77 \\
0.81 \\
0.83 \\
0.82 \\
0.81 \\
0.75 \\
0.66 \\
0.69 \\
0.78 \\
0.91 \\
0.99\end{array}$ & $\begin{array}{l}5 \cdot 2 \\
4 \cdot 0 \\
3 \cdot 8 \\
3 \cdot 9 \\
4 \cdot 1 \\
3 \cdot 6 \\
3 \cdot 7 \\
3 \cdot 8 \\
3 \cdot 9 \\
4 \cdot 6 \\
5 \cdot 0 \\
4 \cdot 7 \\
4 \cdot 0 \\
2 \cdot 9 \\
1 \cdot 2\end{array}$ & $\begin{array}{l}0.76 \\
0.82 \\
0.83 \\
0.87 \\
0.85 \\
0.89 \\
0.88 \\
0.87 \\
0.86 \\
0.79 \\
0.68 \\
0.70 \\
0.79 \\
0.91 \\
0.99\end{array}$ & $\begin{array}{l}5 \cdot 1 \\
4 \cdot 1 \\
3 \cdot 8 \\
3 \cdot 9 \\
4 \cdot 1 \\
3 \cdot 6 \\
3 \cdot 7 \\
3 \cdot 7 \\
3 \cdot 5 \\
3 \cdot 5 \\
3 \cdot 2 \\
2 \cdot 9 \\
2 \cdot 5 \\
2 \cdot 0 \\
0 \cdot 8\end{array}$ & $\begin{array}{l}0.78 \\
0.82 \\
0.84 \\
0.87 \\
0.85 \\
0.89 \\
0.89 \\
0.88 \\
0.89 \\
0.88 \\
0.89 \\
0.90 \\
0.92 \\
0.96 \\
0.99\end{array}$ \\
\hline
\end{tabular}

TABLE II

Residual SDs and correlation coefficients in prediction of adult height from present height, age, and RUS bone age in girls

\begin{tabular}{|c|c|c|c|c|c|c|c|}
\hline \multirow{2}{*}{$\begin{array}{l}\text { Age } \\
(\mathbf{y r})\end{array}$} & \multirow{2}{*}{ No. } & \multicolumn{2}{|c|}{ Height } & \multicolumn{2}{|c|}{ Height + chronological age } & \multicolumn{2}{|c|}{$\begin{array}{l}\text { Height + chronological } \\
\text { age + RUS bone age }\end{array}$} \\
\hline & & $\underset{\text { (cm) }}{\text { Residual SD }}$ & $\mathbf{r}$ & $\underset{(\mathrm{cm})}{\text { Residual SD }}$ & $\mathbf{r}$ & $\underset{(\mathrm{cm})}{\text { Residual SD }}$ & $\mathbf{r}$ \\
\hline $\begin{array}{c}3+ \\
4+ \\
5+ \\
6+ \\
7+ \\
8+ \\
9+ \\
10+ \\
11+ \\
12+ \\
13+ \\
14+ \\
15+\end{array}$ & $\begin{array}{r}34 \\
51 \\
69 \\
89 \\
95 \\
117 \\
123 \\
152 \\
178 \\
214 \\
184 \\
119 \\
71\end{array}$ & $\begin{array}{l}4 \cdot 7 \\
5 \cdot 0 \\
3 \cdot 9 \\
3 \cdot 7 \\
3 \cdot 8 \\
3 \cdot 6 \\
3 \cdot 7 \\
4 \cdot 3 \\
3 \cdot 9 \\
4 \cdot 0 \\
3 \cdot 1 \\
2 \cdot 0 \\
1 \cdot 1\end{array}$ & $\begin{array}{l}0.50 \\
0.63 \\
0.77 \\
0.77 \\
0.79 \\
0.82 \\
0.74 \\
0.64 \\
0.62 \\
0.64 \\
0.80 \\
0.92 \\
0.98\end{array}$ & $\begin{array}{l}2 \cdot 9 \\
4 \cdot 0 \\
3 \cdot 2 \\
3 \cdot 1 \\
3 \cdot 4 \\
3 \cdot 2 \\
3 \cdot 5 \\
4 \cdot 1 \\
3 \cdot 8 \\
3 \cdot 9 \\
3 \cdot 0 \\
1 \cdot 9 \\
1 \cdot 0\end{array}$ & $\begin{array}{l}0.85 \\
0.79 \\
0.86 \\
0.84 \\
0.84 \\
0.86 \\
0.77 \\
0.68 \\
0.65 \\
0.66 \\
0.82 \\
0.93 \\
0.99\end{array}$ & $\begin{array}{l}2 \cdot 9 \\
4 \cdot 0 \\
3 \cdot 1 \\
3 \cdot 0 \\
3 \cdot 2 \\
2 \cdot 9 \\
2 \cdot 9 \\
2 \cdot 9 \\
2 \cdot 9 \\
2 \cdot 7 \\
2 \cdot 3 \\
1 \cdot 4 \\
0 \cdot 8\end{array}$ & $\begin{array}{l}0.85 \\
0.79 \\
0.87 \\
0.86 \\
0.86 \\
0.89 \\
0.85 \\
0.85 \\
0.81 \\
0.85 \\
0.89 \\
0.96 \\
0.99\end{array}$ \\
\hline
\end{tabular}


The accuracy of a prediction equation is judged by the size of the residual standard deviation, which indicates the limits of error of prediction. The equation gives a predicted adult height for an individual, say $170.0 \mathrm{~cm}$; this is the most likely value, but the limits within which the final height will lie in $95 \%$ of cases will be this value \pm twice the residual SD. Because some subjects were included more than once in the regressions, the residual SDs are a little less accurate than their degrees of freedom might indicate; they are not, however, biased.

\section{Results}

In Tables I and II are given the residual standard deviations for the regressions of adult height on (1) present height, (2) present height + exact chronological age, (3) present height + exact chronological age + RUS bone age, together with the correlation coefficients and the number of subject entries (see methods). Comparison of the third and fourth columns of Tables I and II shows that inclusion of exact chronological age into the prediction equation considerably reduced the residual SDs. Evidently it is insufficient to predict the adult height of a 5 -year-old, say, by considering his age as 5.5 years; it is necessary to allow for his being $5 \cdot 1$ or $5 \cdot 9$ years.

Inclusion of bone age into the prediction equation (in the form of RUS, see below) makes no difference to the boys from ages 3 to 9 . But its inclusion begins to lower the residual SD at 10, and from 11 to 16 lowers it greatly; at $14+$, for example, from $4 \cdot 7$ $\mathrm{cm}$ to $2.9 \mathrm{~cm}$. Allowing thus for bone age prevents the diminution of the correlation coefficient between present and adult height which otherwise occurs during the period of the adolescent growth spurt. The same is true in girls; from 3 to 6 the bone age makes little difference but then it becomes increasingly important, and it is essential at ages 9 to 14. There is a sudden lowering of the correlation coefficient in girls at age 11 which we are at a loss to explain, despite careful reconsideration of all our data relating to that age.

Interactions. Other combinations of variables, together with interaction terms (that is terms of the type bone age $\times$ height), were also investigated. Table III shows the results. Here only the average of the residual SDs over the ages 8 to 13 inclusive is given, for boys and girls. The inclusion of the interaction terms (equations 6 to 8) did not result in significant improvement, at least over this age range and in these normal children. However, examination of residual SDs for individual years using equation 6 (which includes interaction RUS $\times$ height) showed a marginally significant reduction at ages 12 in boys and 10 in girls (negative
TABLE III

Regression equations examined for predicting adult height

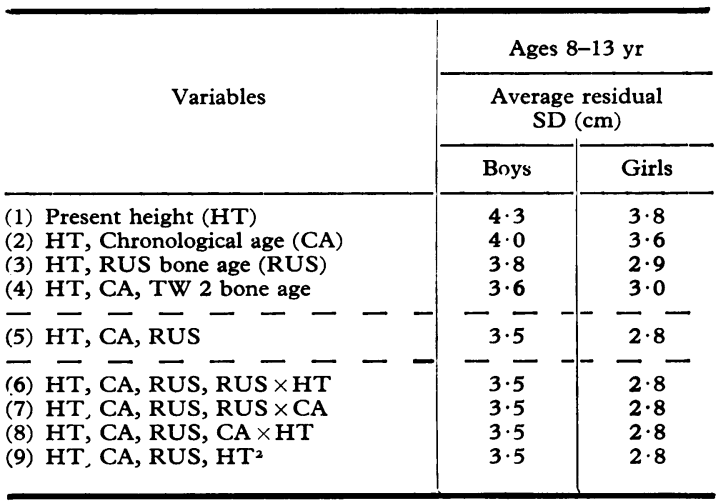

coefficient of interaction term) and at 15 and 16 in boys and 13 in girls (positive coefficient of interaction term). We have not pursued this further at present, but it might be important in considering patients with a pathological degree of bone age delay. The other interactions were ineffective.

Bone age. Equations (4) and (5) in Table III show that bone age computed from the radius, ulna, metacarpals and phalanges only (RUS) predicted better than the full TW 2 system. Table IV com-

TABLE IV

Comparison of TW 1,TW 2, RUS, and carpal bone age in predicting adult height

\begin{tabular}{|c|c|c|c|c|}
\hline & \multicolumn{4}{|c|}{ Residual $S D(\mathrm{~cm})$ from $\mathrm{HT}, \mathrm{CA}, \mathrm{BA}$ when $\mathrm{BA}$ is: } \\
\hline & TW 1 & TW 2 & RUS & Carpals \\
\hline $\begin{array}{l}\text { Boys } \\
8-10 \mathrm{yr} \\
11-13 \mathrm{yr} \\
14-16 \mathrm{yr}\end{array}$ & $\begin{array}{l}3 \cdot 45 \\
4 \cdot 00 \\
3 \cdot 57\end{array}$ & $\begin{array}{l}3 \cdot 44 \\
4 \cdot 00 \\
3 \cdot 37\end{array}$ & $\begin{array}{l}3 \cdot 44 \\
3 \cdot 85 \\
3 \cdot 25\end{array}$ & $\begin{array}{l}3 \cdot 47 \\
4 \cdot 27 \\
3 \cdot 90\end{array}$ \\
\hline $\begin{array}{l}\text { Girls } \\
8-10 \mathrm{yr} \\
11-13 \mathrm{yr} \\
14-16 \mathrm{yr}\end{array}$ & - & $\begin{array}{l}3 \cdot 38 \\
2 \cdot 88 \\
1 \cdot 51\end{array}$ & $\begin{array}{l}3 \cdot 33 \\
2 \cdot 86 \\
1 \cdot 42 \\
\end{array}$ & - \\
\hline
\end{tabular}

pares TW 1 and TW 2, carpal bone age and RUS bone age in three age groupings. The later system, TW 2 , is slightly better than TW 1 ; and excluding the carpals is better than retaining them, particularly at adolescence.

Pooling ages. Various pools of ages were tried, such as $5-7 ; 7-9 ; 5-10 ; 10-14$. Except during 
the early years, pooling significantly increased the residuals, as well as introducing bias. The partial regression coefficients change in a fairly regular fashion with age; indeed it seems probable that reducing the age bands to 0.5 or even 0.2 years would result in some further slight improvement. The use of a chronological-age-squared term in the equation (page 22) did not obviate the effect of age pooling.

Menarche. In the girls at ages 12,13 , and 14 the incorporation of age at menarche significantly improved the prediction. Even when bone age was allowed for, premenarcheal girls of age 13, for example, grew to be taller than their prediction and postmenarcheal girls failed to reach their prediction We thus calculated regressions for pre- and postmenarcheal girls separately at these ages. The further adjustment for actual age at menarche in postmenarcheal girls was so small as to be not worth making.

Smoothed equations. Finally, we have adjusted the partial regression coefficients resulting from fitting the equations involving height, chronological age, and RUS bone age by plotting them and smoothing the curves obtained. The RUS coefficients were so small at early ages that we have dropped them altogether at ages 4 to 7 in boys and 4 to 5 in girls, making prediction at these ages more convenient for the clinician. The coefficients for height were pooled over these ages, as were those for chronological age. At age 3 the coefficients fitted badly with the others, making pooling including this age questionable. We have therefore dropped this age altogether.

The final values of the coefficients are given in Tables V and VI. We have deliberately rounded the coefficients, not wishing to give an impression of accuracy which would be spurious. Half-year age bands have been used, which are sufficient to ensure errors of less than $1 \mathrm{~cm}$ in the predicted height from not having coefficients adjusted to the exact chronological age of the subjects. If finer adjustment is required, linear interpolations may be made. Separate equations have been given for pre- and postmenarcheal girls at ages 11 to 14 inclusive, the 11-year value being estimated by a smoothing procedure. To check on bias in the smoothed coefficients, the correlations between error of prediction, and height, chronological age, and RUS bone age were separately computed at each year of age. None departed significantly from zero. The distributions of errors at all ages were gaussian, within the limits imposed by our numbers.

Accuracy of prediction. The residual standard deviations of Tables V and VI are plotted at each age in Fig. 1. The figure shows how the use of bone age has eliminated any rise of the residual at adolescence, and also how the additional use of menarche in girls decreases the residuals for the postmenarcheal.

The limits of the predicted height in $95 \%$ of subjects should be within \pm twice the residual SD.

TABLE V

Coefficients for prediction of adult height of boys

\begin{tabular}{|c|c|c|c|c|c|c|}
\hline $\begin{array}{l}\text { Age } \\
(\mathrm{yr})\end{array}$ & $\begin{array}{l}\text { Height } \\
(\mathrm{cm})\end{array}$ & $\begin{array}{c}\text { Chronological age } \\
(y \mathbf{r})\end{array}$ & $\underset{(y \mathbf{r})}{\text { Bone age (RUS) }}$ & Constant & $\underset{(\mathrm{cm})}{\text { Residual SD }}$ & $\mathbf{r}$ \\
\hline 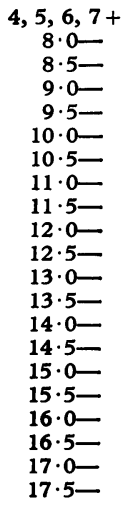 & $\begin{array}{l}1 \cdot 20 \\
1 \cdot 22 \\
1 \cdot 23 \\
1 \cdot 22 \\
1 \cdot 21 \\
1 \cdot 20 \\
1 \cdot 19 \\
1 \cdot 16 \\
1 \cdot 13 \\
1 \cdot 08 \\
1 \cdot 03 \\
0 \cdot 98 \\
0 \cdot 94 \\
0.90 \\
0 \cdot 87 \\
0 \cdot 84 \\
0 \cdot 82 \\
0 \cdot 88 \\
0 \cdot 94 \\
0.96 \\
0.98\end{array}$ & $\begin{array}{l}-7 \cdot 3 \\
-7 \cdot 2 \\
-7 \cdot 0 \\
-6 \cdot 8 \\
-6 \cdot 5 \\
-6 \cdot 2 \\
-5 \cdot 9 \\
-5 \cdot 5 \\
-5 \cdot 1 \\
-4 \cdot 2 \\
-3 \cdot 4 \\
-2 \cdot 6 \\
-1 \cdot 9 \\
-1 \cdot 4 \\
-1 \cdot 0 \\
-0.8 \\
-0.6 \\
-0.4 \\
-0.3 \\
-0.2 \\
-0.1\end{array}$ & $\begin{array}{l}0 \\
-0.4 \\
-0.7 \\
-0 \cdot 8 \\
-0 \cdot 8 \\
-1 \cdot 0 \\
-1 \cdot 2 \\
-1 \cdot 6 \\
-2 \cdot 0 \\
-2 \cdot 6 \\
-3 \cdot 2 \\
-3 \cdot 8 \\
-4 \cdot 4 \\
-4 \cdot 5 \\
-4 \cdot 6 \\
-3 \cdot 8 \\
-3 \cdot 1 \\
-2 \cdot 4 \\
-1 \cdot 8 \\
-1 \cdot 2 \\
-0.7\end{array}$ & $\left.\begin{array}{c}82 \\
82 \\
82 \\
82 \\
82\end{array}\right\}$ & $\begin{array}{l}4 \cdot 0 \\
3 \cdot 6 \\
3 \cdot 6 \\
3 \cdot 6 \\
3 \cdot 5 \\
3 \cdot 5 \\
3 \cdot 1 \\
2 \cdot 9 \\
2 \cdot 5 \\
2 \cdot 0 \\
0.8\end{array}$ & $\begin{array}{l}0.84 \\
0.89 \\
0.89 \\
0.89 \\
0.89 \\
0.88 \\
0.89 \\
0.90 \\
0.92 \\
0.96 \\
0.99\end{array}$ \\
\hline
\end{tabular}


TABLE VI

Coefficients for prediction of adult height of girls

\begin{tabular}{|c|c|c|c|c|c|c|}
\hline $\begin{array}{l}\text { Age } \\
(y r)\end{array}$ & $\begin{array}{l}\text { Height } \\
(\mathrm{cm})\end{array}$ & $\begin{array}{c}\text { Chronological age } \\
(\mathbf{y r})\end{array}$ & $\begin{array}{c}\text { Bone age (RUS) } \\
(\mathrm{yr})\end{array}$ & Constant & $\underset{(\mathrm{cm})}{\text { Residual }} \mathrm{SD}$ & $\mathbf{r}$ \\
\hline $\begin{array}{r}4,5+ \\
6 \cdot 0- \\
6 \cdot 5- \\
7 \cdot 0- \\
7 \cdot 5- \\
8 \cdot 0- \\
8 \cdot 5- \\
9 \cdot 0- \\
9 \cdot 5- \\
10 \cdot 0- \\
10 \cdot 5-\end{array}$ & $\begin{array}{l}0.95 \\
0.95 \\
0.95 \\
0.94 \\
0.93 \\
0.92 \\
0.92 \\
0.92 \\
0.91 \\
0.89 \\
0.87\end{array}$ & $\begin{array}{l}-6 \cdot 5 \\
-6 \cdot 0 \\
-5 \cdot 5 \\
-5 \cdot 1 \\
-4 \cdot 7 \\
-4 \cdot 4 \\
-4 \cdot 0 \\
-3 \cdot 8 \\
-3 \cdot 6 \\
-3 \cdot 2 \\
-2 \cdot 7\end{array}$ & $\begin{array}{c}0 \\
-0 \cdot 4 \\
-0 \cdot 8 \\
-1 \cdot 0 \\
-1 \cdot 1 \\
-1 \cdot 5 \\
-1 \cdot 9 \\
-2 \cdot 3 \\
-2 \cdot 7 \\
-3 \cdot 2 \\
-3 \cdot 6\end{array}$ & $\left.\begin{array}{r}93 \\
93 \\
93 \\
94 \\
94 \\
95 \\
96 \\
99 \\
102 \\
106 \\
109\end{array}\right\}$ & $\begin{array}{l}3 \cdot 5 \\
3 \cdot 0 \\
3 \cdot 2 \\
2 \cdot 9 \\
2 \cdot 8 \\
2 \cdot 9\end{array}$ & $\begin{array}{l}0.85 \\
0.86 \\
0.85 \\
0.89 \\
0.85 \\
0.85\end{array}$ \\
\hline $\begin{array}{r}\text { Premenarcheal } \\
11 \cdot 0- \\
11 \cdot 5- \\
12 \cdot 0- \\
12 \cdot 5- \\
13 \cdot 0 \text { - } \\
13 \cdot 5- \\
14 \cdot 0- \\
14 \cdot 5-\end{array}$ & $\begin{array}{l}0.83 \\
0.82 \\
0.83 \\
0.83 \\
0.85 \\
0.87 \\
0.91 \\
0.95\end{array}$ & $\begin{array}{l}-2 \cdot 6 \\
-2 \cdot 5 \\
-2 \cdot 4 \\
-2 \cdot 3 \\
-2 \cdot 0 \\
-1 \cdot 8 \\
-1 \cdot 6 \\
-1 \cdot 4\end{array}$ & $\begin{array}{l}-3 \cdot 6 \\
-3 \cdot 6 \\
-3 \cdot 4 \\
-3 \cdot 3 \\
-3 \cdot 1 \\
-3 \cdot 0 \\
-2 \cdot 8 \\
-2 \cdot 5\end{array}$ & $\left.\begin{array}{r}114 \\
115 \\
111 \\
108 \\
98 \\
90 \\
79 \\
67\end{array}\right\}$ & $\begin{array}{l}2 \cdot 9 \\
2 \cdot 7 \\
2 \cdot 2 \\
1 \cdot 2\end{array}$ & $\begin{array}{r}0.82 \\
0.87 \\
.92 \\
0.94\end{array}$ \\
\hline $\begin{array}{c}\text { Postmenarcheal } \\
11 \cdot 0 \text { - } \\
11 \cdot 5- \\
12 \cdot 0- \\
12 \cdot 5- \\
13 \cdot 0 \text { - } \\
13 \cdot 5- \\
14 \cdot 0 \text { - } \\
14 \cdot 5-\end{array}$ & $\begin{array}{l}0.87 \\
0.89 \\
0.91 \\
0.93 \\
0.95 \\
0.96 \\
0.96 \\
0.97\end{array}$ & $\begin{array}{l}-2 \cdot 3 \\
-1 \cdot 9 \\
-1 \cdot 4 \\
-1 \cdot 0 \\
-0.9 \\
-0.9 \\
-0.8 \\
-0.8\end{array}$ & $\begin{array}{l}-3 \cdot 3 \\
-3 \cdot 3 \\
-3 \cdot 2 \\
-2 \cdot 7 \\
-2 \cdot 2 \\
-1 \cdot 8 \\
-1 \cdot 4 \\
-1 \cdot 3\end{array}$ & $\left.\begin{array}{r}100 \\
91 \\
82 \\
67\end{array}\right\}$ & $\begin{array}{l}2 \cdot 6^{\star} \\
2 \cdot 1 \\
1 \cdot 6 \\
1 \cdot 2\end{array}$ & $\begin{array}{l}0.87^{\star} \\
0.89 \\
0.94 \\
0.97\end{array}$ \\
\hline $\begin{array}{l}\text { All girls } \\
\qquad \begin{array}{l}15 \cdot 0- \\
15 \cdot 5-\end{array}\end{array}$ & $\begin{array}{l}0.98 \\
0.99\end{array}$ & $\begin{array}{l}-0 \cdot 6 \\
-0 \cdot 4\end{array}$ & $\begin{array}{l}-1 \cdot 1 \\
-0 \cdot 7\end{array}$ & $\left.\begin{array}{l}30 \\
20\end{array}\right\}$ & 0.8 & 0.99 \\
\hline
\end{tabular}

$\star$ Value estimated.

In the boys studied the predictions fell within approximately $\pm 7 \mathrm{~cm}$ of actual adult height in those of ages up to $12+, \pm 6 \mathrm{~cm}$ at ages 13 and $14, \pm 5 \mathrm{~cm}$ at age 15 , and $\pm 4 \mathrm{~cm}$ at age 16 . The $95 \%$ range of adult male height is $\pm 12.5 \mathrm{~cm}$, so the use of the prediction equation considerably narrowed the target area. In girls the corresponding limits of error were about $\pm 6 \mathrm{~cm}$ up to age $11 ; \pm 5 \mathrm{~cm}$ at age 12 if premenarcheal and $\pm 4 \mathrm{~cm}$ if postmenarcheal; $\pm 4 \mathrm{~cm}$ at age 13 if premenarcheal and $\pm 3 \mathrm{~cm}$ if postmenarcheal; and $\pm 2 \mathrm{~cm}$ at age 14 . The $95 \%$ range of adult female height is $\pm 11.5 \mathrm{~cm}$. Considered as coefficients of variation the error of estimate was about $\pm \mathbf{2} \cdot 0 \%$ of the mean for boys up to age 12 reducing to $\pm 1.7 \%$ at ages 13 and 14 ; and $\pm 1.8 \%$ for the girls up to age 11 , reducing to $\pm 1.4 \%$ at ages 12 and 13 for premenarcheal and $1 \cdot 1 \%$ if postmenarcheal.

Prediction of height of ballet dancers. The equations of Table VI have been used to predict the height of 62 girls who entered the Royal Ballet
School between the ages of $9+$ and $12+$ and whose final height was also measured. 7 of them were predicted from height at age 9, 22 each from 10 and 11 , and 11 from age 12 . Fig. 2 shows the distribution of errors (see also Table $\mathrm{X}$ below). The results accord well with expectation.

Allowance for parental heights. Unfortunately measured parental heights were only available for a minority of our children and so we have been unable to include midparent height, as we would wish, in our prediction equation. However, we have computed the regressions at each year of age between the errors of estimate (actual less predicted adult height) and midparent height. The results are shown in Table VII.

The number of cases is so small that generalizations are hazardous. It does appear, however, that there was a just significant relation $(P=0.05)$ with a regression coefficient of about 0.3 to 0.4 over the ages 9 to 14 in the boys and 7 to 13 in the girls. We thus propose to allow for parents' heights by adding 

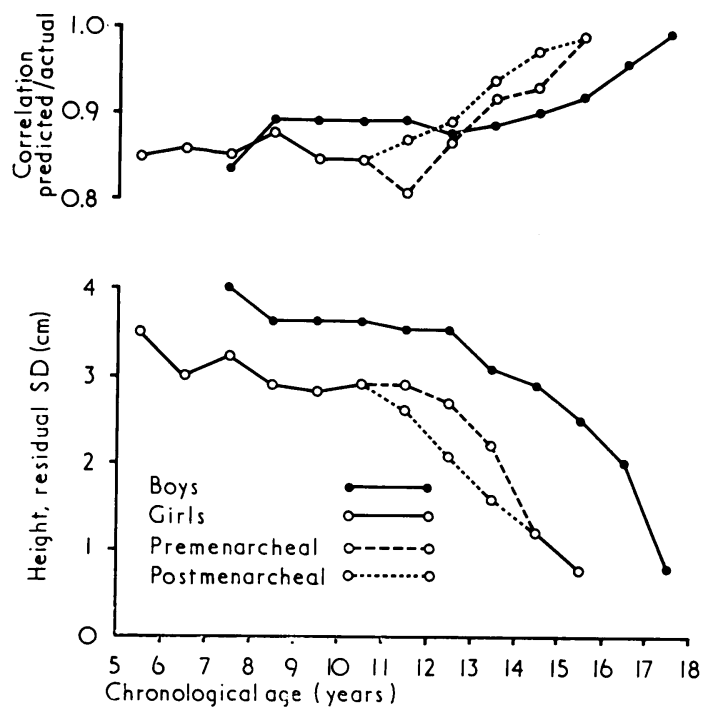

FIG. 1.-Residual standard deviations about prediction, from Tables $V$ and VI, with correlation coefficients between predicted and achieved adult height.

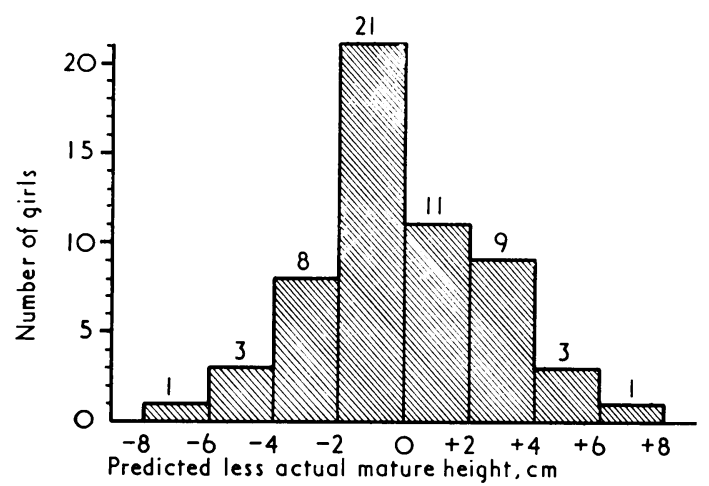

FIG. 2.-Distribution of errors of prediction of adult height from height, RUS bone age, and menarche at ages 9 to $12+$ in 62 entrants to ballet school.

to the estimate derived from Tables $\mathrm{V}$ or VI one-third of the amount that the midparent height deviates from the mean midparent height (which was $168 \mathrm{~cm}$ in our data). The standard deviation of midparent height is about $6.0 \mathrm{~cm}$. Thus for very large parents, with a midparent height 2 standard deviations above average for the population, we add $4 \mathrm{~cm}$ to the estimate, and for correspondingly small parents we subtract $4 \mathrm{~cm}$. Usually the correction would be less than this.

At earlier ages in boys ( 4 to 7 ) the adjustment might be larger, one-half of the midparent deviation
TABLE VII

Regression of error of estimate (actual less predicted) on midparent height

\begin{tabular}{|c|c|c|c|c|c|c|c|}
\hline & \multicolumn{2}{|c|}{ Boys } & \multirow[b]{2}{*}{$r$} & \multicolumn{3}{|c|}{ Girls } & \multirow[b]{2}{*}{$r$} \\
\hline Age & No. & b & & Age & No. & b & \\
\hline $4+$ & 21 & 0.52 & $0 \cdot 60$ & $4+$ & 20 & 0.42 & 0.45 \\
\hline $5+$ & 19 & 0.40 & 0.52 & $5+$ & 18 & 0.20 & 0.22 \\
\hline $6+$ & 31 & 0.60 & 0.63 & $6+$ & 23 & 0.21 & 0.33 \\
\hline $7+$ & 22 & $0 \cdot 60$ & 0.62 & $7+$ & 16 & 0.38 & 0.39 \\
\hline $8+$ & 25 & $0 \cdot 19$ & $0 \cdot 28$ & $8+$ & 24 & $0 \cdot 14$ & 0.19 \\
\hline $9+$ & 21 & $0 \cdot 26$ & $0 \cdot 32$ & $9+$ & 23 & 0.40 & 0.51 \\
\hline $10+$ & 23 & 0.27 & $0 \cdot 36$ & $10+$ & 20 & 0.11 & $0 \cdot 16$ \\
\hline $11+$ & 22 & 0.32 & 0.46 & $11+$ & 15 & 0.45 & 0.53 \\
\hline $12+$ & 30 & 0.44 & 0.49 & $12+$ & 25 & 0.44 & 0.53 \\
\hline $13+$ & 19 & 0.36 & 0.47 & $13+$ & 16 & 0.23 & 0.49 \\
\hline $14+$ & 14 & 0.32 & 0.52 & & & & \\
\hline
\end{tabular}

being added or subtracted. Use of the adjustment might be expected to reduce the residual SDs by the order of $0.2 \mathrm{~cm}$.

Allowance for age at peak height velocity. The regression of deviation from prediction on age at peak height velocity (PHV) was also significant and positive in both sexes. Boys aged 7 to 14 who were late maturing by this criterion grew to be taller than prediction by about $1 \mathrm{~cm}$ per year of delay in PHV, and early-maturers ended about $1 \mathrm{~cm}$ below prediction for each year PHV was advanced.

Equations based on RUS bone age bands. The use of chronological age as the basis of the equations raises difficulties in subjects with considerable delay in development. If one wishes to predict the final height of a boy aged 18 who is still growing, there is simply no place to look him up in Table V. The obvious thing would be to enter the table at his bone age, say 15 , instead of his chronological age, but the error in doing this is unknown.

Tables VIII and IX give the smoothed partial regression coefficients based on classification by half 'year' of RUS bone age. These equations (in contrast to those in Tables $\mathrm{V}$ and $\mathrm{VI}$ ) give only coefficients for height and chronological age, since including a bone age coefficient did not further decrease the residuals. These bone age-based equations predict height just as well as the chronological age-based ones of Table V and VI except at bone ages 13 and 14 in boys and 12 and 13 in girls. A warning should be given, however, in respect of errors in bone age. The residuals of Tables VIII and IX are derived from the bone age ratings of two experienced raters only, and less experienced raters would increase the errors of prediction by increasing the errors of bone age classification. No such 
TABLE VIII

Coefficients for prediction of adult height of boys, based on RUS bone age classification

\begin{tabular}{|c|c|c|c|c|c|}
\hline $\begin{array}{c}\text { RUS bone age } \\
(y r)\end{array}$ & $\begin{array}{l}\text { Height } \\
\text { (cm) }\end{array}$ & $\begin{array}{c}\text { Chronological age } \\
(y r)\end{array}$ & Constant & $\underset{(\mathrm{cm})}{\text { Residual SD }}$ & $\mathbf{r}$ \\
\hline $\begin{array}{l}4+ \\
5 \cdot 0- \\
5 \cdot 5- \\
6 \cdot 0- \\
6 \cdot 5- \\
7 \cdot 0- \\
7 \cdot 5- \\
8 \cdot 0- \\
8 \cdot 5- \\
9 \cdot 0- \\
9 \cdot 5- \\
10 \cdot 0- \\
10 \cdot 5- \\
11 \cdot 0- \\
11 \cdot 5- \\
12 \cdot 0- \\
12 \cdot 5- \\
13 \cdot 0- \\
13 \cdot 5- \\
14 \cdot 0- \\
14 \cdot 5- \\
15 \cdot 0- \\
15 \cdot 5- \\
16 \cdot 0- \\
16 \cdot 5-\end{array}$ & $\begin{array}{l}1 \cdot 32 \\
1.31 \\
1.30 \\
1.29 \\
1.28 \\
1.26 \\
1.25 \\
1.24 \\
1 \cdot 22 \\
1.21 \\
1 \cdot 20 \\
1.18 \\
1.15 \\
1.12 \\
1.10 \\
1.07 \\
1.04 \\
1.02 \\
1.01 \\
0.99 \\
0.97 \\
0.96 \\
0.96 \\
0.97 \\
0.98\end{array}$ & $\begin{array}{l}-7 \cdot 9 \\
-7 \cdot 7 \\
-7 \cdot 5 \\
-7 \cdot 4 \\
-7 \cdot 2 \\
-7 \cdot 0 \\
-6 \cdot 8 \\
-6 \cdot 6 \\
-6 \cdot 4 \\
-6 \cdot 0 \\
-5 \cdot 7 \\
-5 \cdot 4 \\
-5 \cdot 2 \\
-4 \cdot 8 \\
-4 \cdot 5 \\
-4 \cdot 0 \\
-3 \cdot 4 \\
-3 \cdot 0 \\
-2 \cdot 6 \\
-2 \cdot 3 \\
-2 \cdot 0 \\
-1 \cdot 8 \\
-1 \cdot 5 \\
-1 \cdot 4 \\
-1 \cdot 2\end{array}$ & 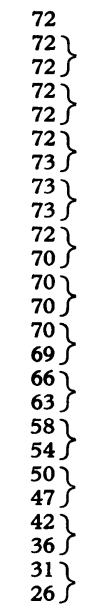 & $\begin{array}{l}3 \cdot 5 \\
4 \cdot 5 \\
3 \cdot 8 \\
3 \cdot 6 \\
3 \cdot 8 \\
3 \cdot 7 \\
3 \cdot 5 \\
3 \cdot 5 \\
3 \cdot 6 \\
3 \cdot 6 \\
3 \cdot 7 \\
2 \cdot 2 \\
1 \cdot 2\end{array}$ & $\begin{array}{l}0.85 \\
0.83 \\
0.82 \\
0.83 \\
0.86 \\
0.87 \\
0.90 \\
0.89 \\
0.88 \\
0.88 \\
0.84 \\
0.95 \\
0.98\end{array}$ \\
\hline
\end{tabular}

TABLE IX

Coefficients for prediction of adult height of girls, based on RUS bone age classification

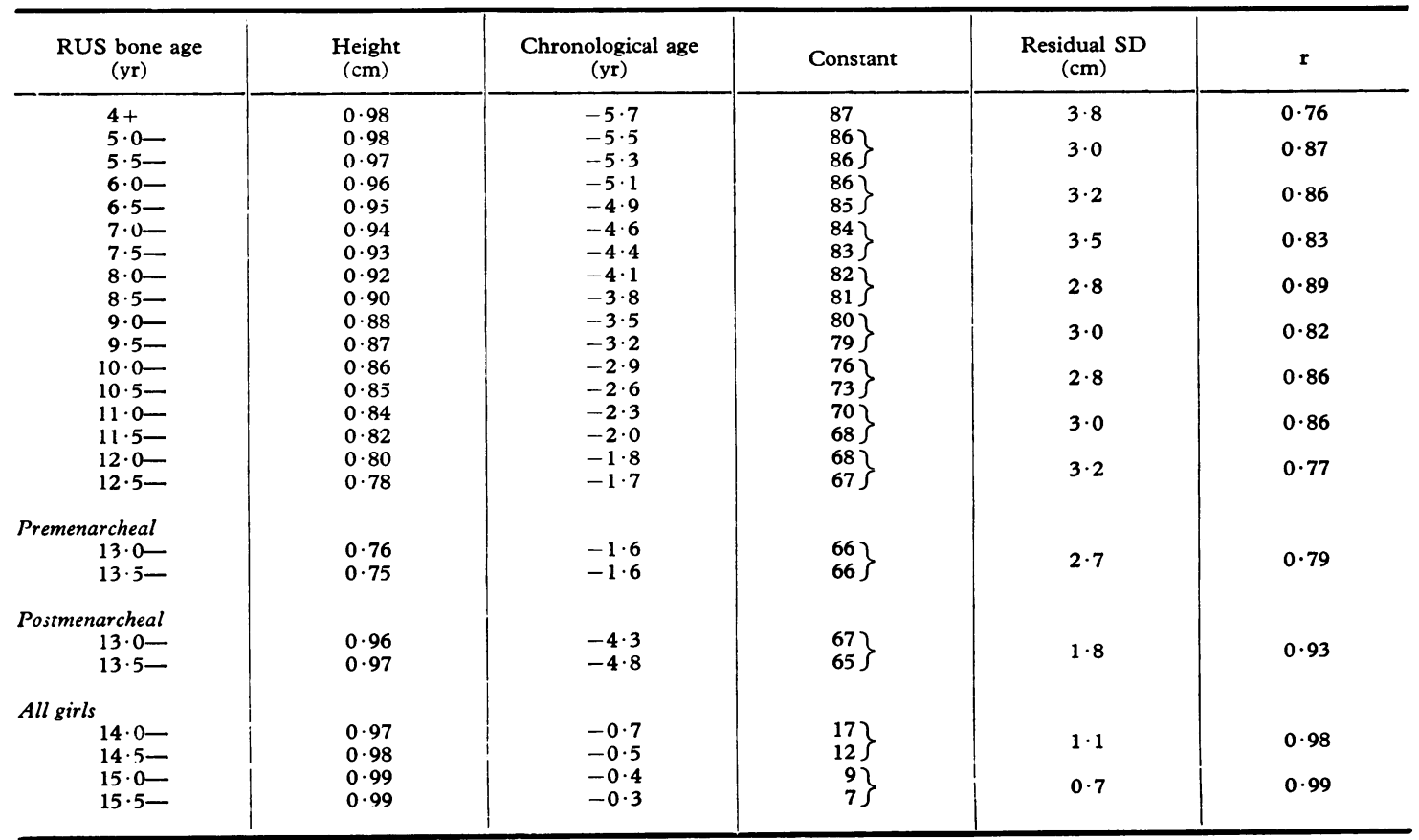


disadvantage occurs in the chronological age-based predictions, since no error should occur in the determination of chronological age.

Separate equations for pre- and postmenarcheal girls are given only at age 13 for the bone age-based predictions. This is because the closer relation of menarche to bone age than to chronological age precluded useful numbers of available subjects with bone age $12+$ with menarche, or bone age $14+$ without it.

Comparison of chronological age-based and bone age-based predictions. The two scales are so constructed that they give the same prediction for children of mean height and mean bone age. They also give approximately the same result for children who are tall or short but of bone age equal to chronological age. However, when RUS bone age and chronological age are different the two systems lead to different results. The CA-based system decreases the prediction as bone age advances and increases it as bone age is delayed in a linear fashion at each age. Thus for a girl aged 10.5 years and of average height the CA based prediction is $165 \mathrm{~cm}$ if bone age equals chronological age, $158 \mathrm{~cm}$ if bone age is 2 years advanced, and $172 \mathrm{~cm}$ if bone age is 2 years delayed. The bone age-based system does not do this. In the BA-based system the predictions are less affected by bone age discrepancies but the effect is not symmetrical. Retardation of bone age is little weighted, so that a considerable discrepancy of prediction arises in comparison with the CA-based scales in the case of a delayed child (amounting typically to $3-4 \mathrm{~cm}$ for a 2-year delay). Advancement is weighted somewhat more, so that in advanced children agreement with the CA-based scale is better (discrepancies being typically $2 \mathrm{~cm}$ for a 2 -year advance). The distribution of errors of prediction from the BA-based scale for the ballet entrants shown in Fig. 2 is given in Table $X$.

Worked examples. (1) Suppose a boy is referred who is worried about his short stature. He is aged 12.5 years and has a height of $136.0 \mathrm{~cm}$, a little below the 3rd centile. His RUS bone age turns out to be 11.0 'years'. His parents heights are $170.0 \mathrm{~cm}\left(5^{\prime} 6^{\prime \prime}\right)$ and $160.0 \mathrm{~cm}$ $\left(5^{\prime} 3^{\prime \prime}\right)$. He is thus a typical case of the small/delay diagnosis (Tanner, 1973).

From Table V, his predicted height is given as $136 \cdot 0 \times 1 \cdot 03-12 \cdot 5 \times 3 \cdot 4-11 \cdot 0 \times 3 \cdot 2+103 \cdot 0=165 \cdot 3$ $\mathrm{cm}$. This is at about the 10 th centile of adult height; the parents however are at the 25 th centile and 30 th centile; thus midparent height is $165.0 \mathrm{~cm}$ which is $3.0 \mathrm{~cm}$ below the local average of 168.0 . Thus $\frac{1}{3}$ of $3.0 \mathrm{~cm}=1.0 \mathrm{~cm}$ should be subtracted to allow for parents' heights. The
TABLE X

Distribution of errors of prediction of adult height by various methods in 57 ballet school entrants. (Girls predicted at $C A$ 9-12+; $B A$ 7-13+)

\begin{tabular}{c|c|c|c}
\hline $\begin{array}{c}\text { Predicted-actual } \\
\text { height } \\
(\mathrm{cm})\end{array}$ & $\begin{array}{c}\text { CA based: } \\
\text { Table VI }\end{array}$ & $\begin{array}{c}\text { BA based: } \\
\text { Table IX }\end{array}$ & Bayley-Pinneau \\
\hline+10 & 0 & 0 & 1 \\
+8 & 0 & 0 & 0 \\
+6 & 1 & 1 & 3 \\
$+4-$ & 3 & 2 & 6 \\
$+2-$ & 9 & 12 & 10 \\
$0-$ & 11 & 13 & 10 \\
$-0-$ & 21 & 16 & 17 \\
$-4-$ & 8 & 9 & 7 \\
$-6-$ & 3 & 2 & 0 \\
$-8-$ & 1 & 1 & 0 \\
\hline
\end{tabular}

final prediction is therefore $164 \cdot 3 \mathrm{~cm}\left(5^{\prime} 5^{\prime \prime}\right)$. The limits of accuracy are given by twice the residual standard deviation at age 12.5 which is $3.5 \mathrm{~cm}$ in Table V. The report should read: 'most likely final adult height is estimated as $164 \cdot 3 \mathrm{~cm}\left(5^{\prime} 5^{\prime \prime}\right)$ with possible limits of $157 \cdot 3 \mathrm{~cm}\left(5^{\prime} 2^{\prime \prime}\right)$ and $171 \cdot 3 \mathrm{~cm}\left(5^{\prime} 8^{\prime \prime}\right) .^{\prime}$ This implies that his centile position at referral is extremely unlikely to be worsened, and most probably will be increased to about the 10th, with just a chance of reaching the 40th. On this basis reassurance is possible.

A second example might concern a girl fearing she will be too tall when grown up. She is aged $12 \cdot 0$ years at referral and has a height of $165.2 \mathrm{~cm}$, which is about the 97th centile. Her RUS bone age is $14 \cdot 0$, however, though she is premenarcheal. Her height prediction from Table VI, is $165 \cdot 2 \times 0 \cdot 83-12 \cdot 0 \times 2 \cdot 4-14 \cdot 0 \times 3 \cdot 4+$ $111 \cdot 0=171 \cdot 7 \mathrm{~cm}\left(5^{\prime} 7 \frac{1^{\prime \prime}}{2}\right)$. This is just beyond the 90th centile, and well within normal limits. If the parents were both at the 97th centile (as is not uncommon in such subjects) then the midparent height would be 180 $\mathrm{cm}$ or $12 \mathrm{~cm}$ above the mean of $168 \mathrm{~cm}$. Thus approximately $4 \mathrm{~cm}$ (one-third of 12) should be added to allow for this, giving $176 \mathrm{~cm}\left(5^{\prime} 10^{\prime}{ }^{\prime \prime}\right)$, which is a little over the 97th centile. The limits associated with this estimate are twice $2 \cdot 7 \mathrm{~cm}$, thus $166 \mathrm{~cm}$ to $177 \mathrm{~cm}$ without allowing for parents, or approximately 171 to 181 $\mathrm{cm}$ allowing for parents. These predictions should be used in making the decision as to whether to give oestrogen. If the girl had been post- instead of premenarcheal her predicted height would have been only slightly smaller, $170.7 \mathrm{~cm}$, but the confidence limits would have been considerably narrower, the residual SD being $2 \cdot 1 \mathrm{~cm}$ instead of $2 \cdot 7 \mathrm{~cm}$. Then the $95 \%$ limits would have been 166.5 to $174.9 \mathrm{~cm}$ allowing a further reassurance as to the maximal height likely to be reached.

\section{Discussion}

The chief points that need discussion concern the accuracy and applicability of the predictions. 
Prediction of adult height

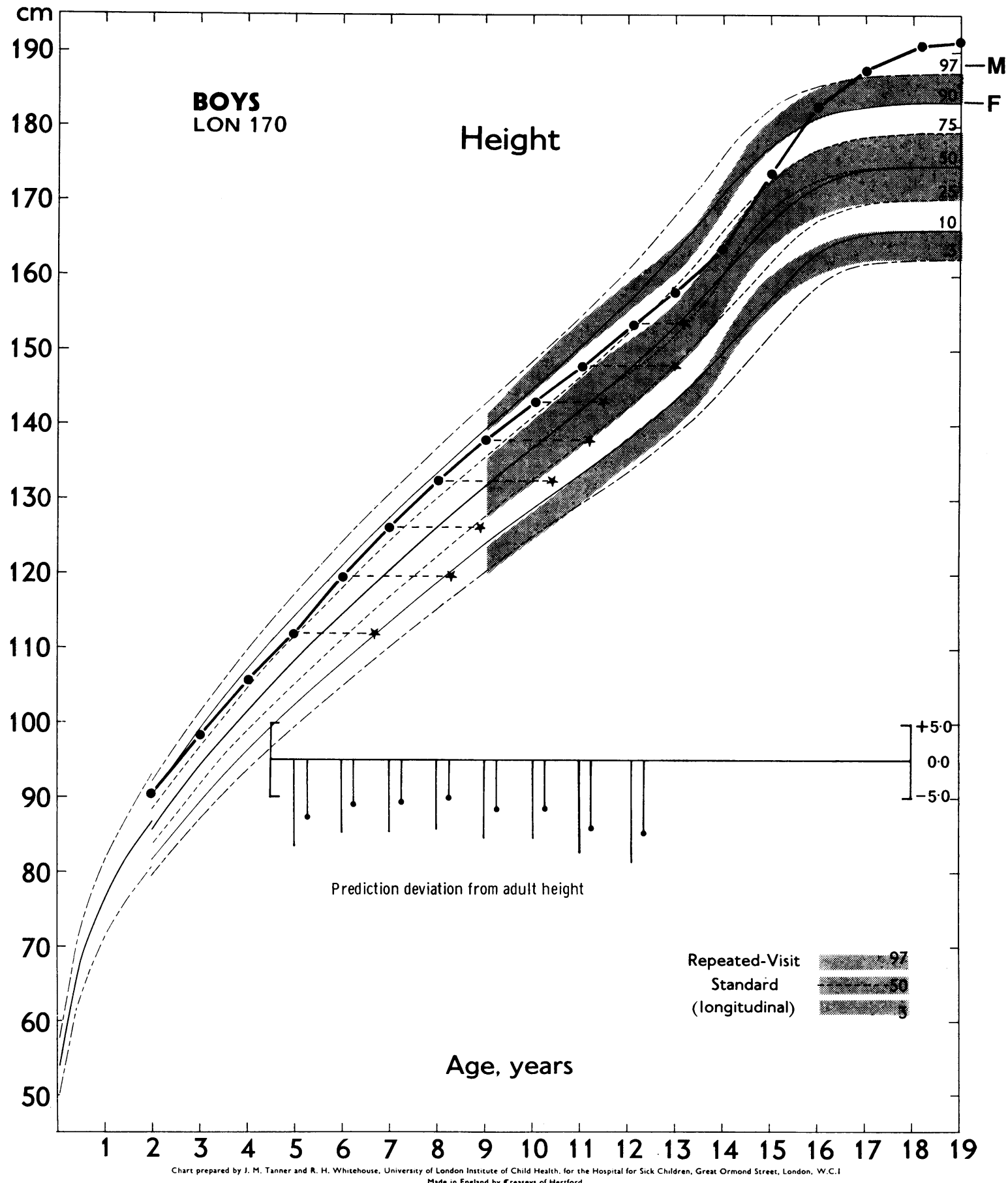

FIG. 3.--Growth curve of normal but unusual subject with deviations of predicted from actual adult height. The lines with points at the end represent the prediction allowing for midparent height. This represents the worst prediction in our series. 
Accuracy. The equations permit a prediction of adult height which in $95 \%$ of instances is within $\pm 7 \mathrm{~cm}$ of true adult height in boys aged 4 to 12 and $\pm 6 \mathrm{~cm}$ in girls aged 4 to 11 . At older ages the errors progressively diminish and the limits for boys aged 14 are $\pm 6 \mathrm{~cm}$ and for girls aged 13 are $\pm 4 \mathrm{~cm}$, if premenarcheal, or $\pm 3 \mathrm{~cm}$ if postmenarcheal. The inclusion of bone age in the equations satisfactorily compensates for the effect of the adolescent growth spurt so that no worsening of the prediction takes place at that time; indeed once the growth spurt has started prediction rapidly improves. In girls the prediction is better for those who are postmenarcheal than those of a similar age who have not yet begun to menstruate. Inclusion of midparent height further improves the predictions, but the actual amount by which it does so and the best way of making the adjustment needs further study in a much larger group of parents than was available to us. We must emphasize that for such a study both parents need actually to be measured by the investigators; heights derived from hearsay (especially father's height) are often quite inaccurate.

The errors of prediction are in general a little smaller than those arising from the Bayley-Pinneau predictions and considerably smaller in the case of postmenarcheal girls. Inclusion of midparent height allowance brings the errors down some $10 \%$ further.

A smaller further improvement can be obtained in our data by allowing for age of peak height velocity in boys, as Walker (1974) has shown in a longitudinal series unfortunately lacking $x$-rays and thus not adequately predicted at adolescence. In clinical work, however, the age of peak height velocity is seldom known with the necessary accuracy. Inclusion of the velocity of height growth, in the year previous to that being predicted from, improved Walker's estimates somewhat, but had little effect on ours.

Though our predictions seem to be the best available to date, they nevertheless leave a lot to be desired. We have searched for ways of improving them, but to date have found none, probably because we do not know what causes the remaining unpredictability. It may be that variations in the actual amount of height gained in the adolescent spurt are responsible. This amount is largely independent of the amount of growth before the spurt, especially in boys (Tanner, 1973; Tanner et al., 1976) and one could speculate that it may be inherited independently. If so, we would need to know the amount of height gained during the adolescent spurt of the parents. We have correlated the peak height velocity $(\mathrm{cm} / \mathrm{yr})$ with the deviation from prediction in our series. In girls the correlation was zero, but in boys it was significant and positive at ages 5 to 9 . Thus boys with a large peak height velocity were underpredicted slightly, but the regression coefficient was too low for this factor to account for much of the remaining uncertainty.

One practical point may be noticed. The $\stackrel{\Phi}{\circ}$ predicted adult height of an older child will occasionally be actually below the height he or she has already attained. This is an inevitable consequence of the large residual deviations and should cause no alarm. In any event the reporting of expected adult height of a child should be in the form 'most likely adult height $160.0 \mathrm{~cm}$; possible limits $157 \cdot 0$ to $163 \cdot 0 \mathrm{~cm}$ '.

Applicability. Strictly speaking the equations are only valid for children who are within the same normal limits for height and bone age as the standardizing group. They should not be extrapolated to predict the height of excessively tall or short children or those who are advanced or retarded to a really pathological degree, without the utmost caution. This is a frustrating limitation and applies even more to the Bayley-Pinneau predictions than to ours, since their allowances are less quantitative. Even some normal subjects present problems, as Fig. 3 shows. This boy grew mostly along the 80th centile, but with a considerably advanced bone age. In consequence, the equations predicted his final height at around the 75th centile. However, a very large adolescent spurt upset entirely this prediction and his final height was above the 97th centile. In this instance, but not in the majority of others, a prediction based solely on midparent height would have worked better. This case, with a prediction error of $10-12 \mathrm{~cm}$, is the worst in all our normal growth study series.

In the clinic two situations are of chief importance. First, there is the prediction of the adult height of tall girls as a prelude to a trial of oestrogen treatment. Second, there is the prediction of the adult height of small and delayed children as an aid to reassurance and control or correction by anabolic steroid treatment. Roche and Wettenhall (1969) used the Bayley-Pinneau tables to predict final height of 29 untreated girls said to be tall, but only 7 of them were actually above the 97 th centile. These 7 can be identified; they were on average overpredicted by $0.7 \mathrm{~cm}$, which was a little more than the others, but a modest enough amount. It seems likely, though not at present certain, that most girls requesting oestrogen treatment would be fairly correctly predicted by our equations. 


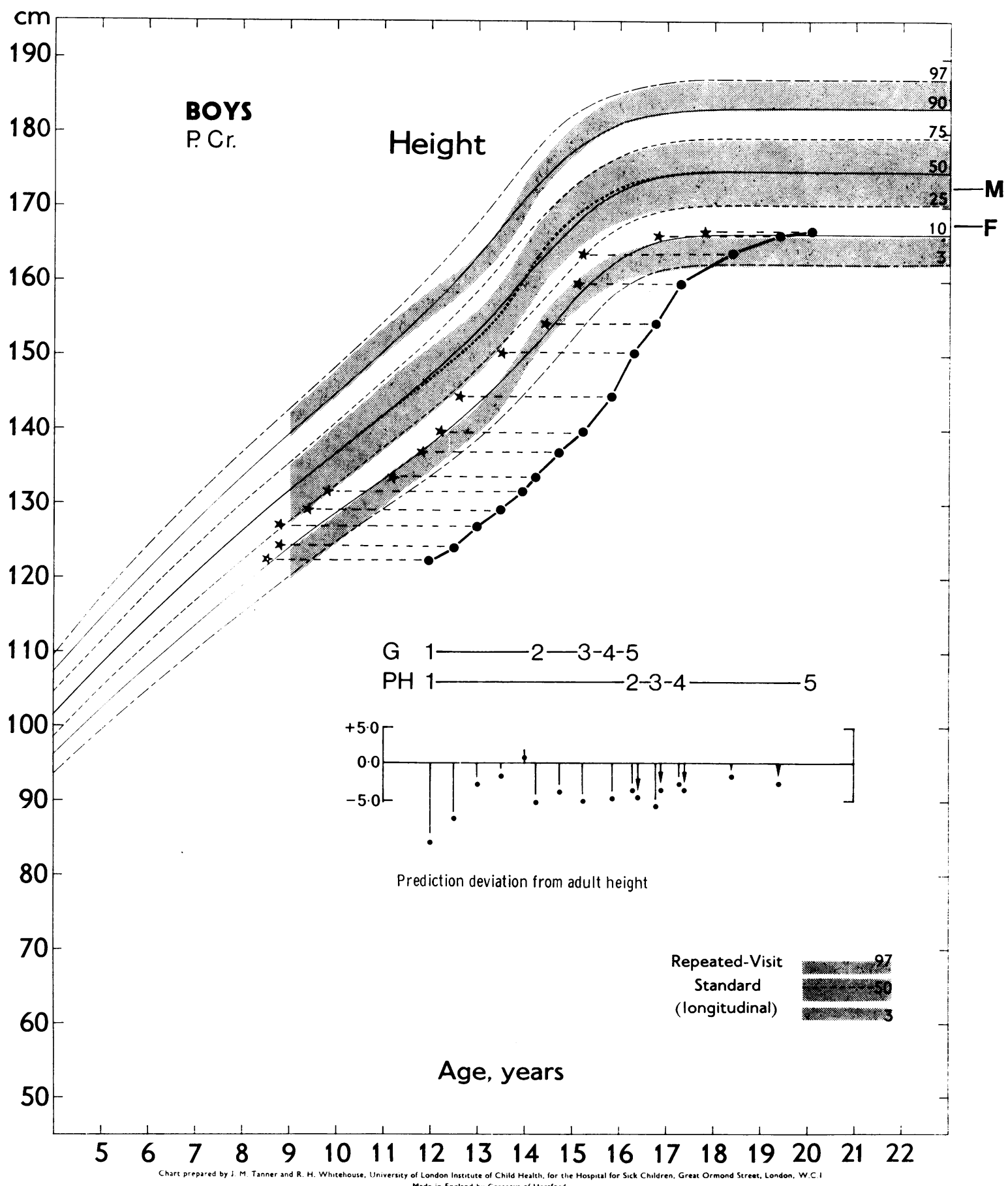

FIG. 4.-Growth curve and height predictions of a boy with short stature and growth delay. 
The second situation concerns the prediction of adult height of boys with short stature and delay in maturation. An example is shown in Fig. 4. All predictions except the first two are within $4 \mathrm{~cm}$ of actual height attained. The adjustment for parents' heights worsens slightly the prediction at most ages. The predictions illustrated are chronological agebased except for those with arrows, which are RUS-based.

In more pathological cases such as Turner's syndrome these equations do not apply; nor do they have value in controlling treatment in such conditions as hypothyroidism or isolated growth hormone deficiency, where the midparent height centile is the best, though very fallible, guide to the potential adult height.

Chronological age-based and bone agebased equations. We can make little comment at present on the relative merits of the two systems presented here. The CA-based makes more allowance for bone age advancement or retardation and looks at first sight the more sensible. At bone ages 12 and 13 in girls and 14 in boys the bone aged-based predictions seem clearly worse. Thus a girl of bone age 12 and chronological age 14 is best looked up according to chronological age; but if the chronological age is 15 or 16 then the bone age base may be used. Table $\mathrm{X}$ shows that for our ballet girls the two systems worked equally well, but a full trial of both systems on other longitudinal series of data is very desirable.

We gratefully acknowledge the helpful criticisms of Professor A. Prader, Mr. M. J. R. Healy, and Dr. C. G. D. Brook, and the financial support of the Medical Research Council and the Nuffield Foundation.

\section{REFERENCES}

Bayley, N. (1946). Tables for predicting adult height from skeletal age and present height. Fournal of Pediatrics, 28, 49.

Bayley, N. (1954). Some increasing parent-child similarities during the growth of children. Fournal of Educational Psychology, 45, 1.

Bayley, N. (1962). The accurate prediction of growth and adult height. Modern Problems in Paediatrics, 7, 234.

Bayley, N., and Pinneau, S. R. (1952). Tables for predicting adult height from skeletal age: revised for use with the Greulich-Pyle hand standards. Fournal of Pediatrics, 40, 423. (Erratum corrected in Fournal of Pediatrics, 1952, 41, 371.)

Fisher, R. A. (1918). The correlation between relatives on the supposition of Mendelian inheritance. Transactions of the Royal Society (Edinburgh), 52, 399.
Greulich, W. W., and Pyle, S. I. (1959). Radiographic Atlas of $\supseteq$ Skeletal Development of the Hand and Wrist, 2nd ed. Stanford University Press, Stanford.

Marshall, W. A. (1974). Interrelationships of skeletal maturation $\overrightarrow{\bar{F}}$ sexual development and somatic growth in man. Annals of $\vec{\oplus}$ Human Biology, 1, 29.

Marshall, W. A., and Tanner, J. M. (1969). Variations in the pattern of pubertal changes in girls. Archives of Disease in $\overline{\bar{O}}$ Childhood, 44, 291.

Marshall, W. A., and Tanner, J. M. (1970). Variations in the pattern of pubertal changes in boys. Archives of Disease in 0 Childhood, 45, 13.

Moore, T., Hindley, C. B., and Falkner, F. (1954). A longitudinal थ research in child development and some of its problems. British Medical fournal, 2, 1132.

Roche, A. F., and Davila, G. H. (1972). Late adolescent growth in stature. Pediatrics, 50, 874.

Roche, A. F., and Wettenhall, H. N. B. (1969). The prediction of adult stature in tall girls. Australian Paediatric Fournal, 5, 13. ه

Tanner, J. M. (1962). Growth at Adolescence, 2nd ed., p. 88. O Blackwell Scientific Publications, Oxford; Thomas, Springfield, ? Illinois.

Tanner, J. M. (1973). Physical growth and development. In :Textbook of Paediatrics. Edited by J. O. Forfar and G. C. Arneil. Churchill Livingstone, Edinburgh and London.

Tanner, J. M., Goldstein, H., and Whitehouse, R. H. (1970). Standards for children's height at ages 2 to 9 years, allowing for $\supset$ height of parents. Archives of Disease in Childhood, 45, 755.

Tanner, J. M., Healy, M. J. R., Lockhart, R. D., MacKenzie, J. D., c and Whitehouse, R. H. (1956). Aberdeen Growth Study I. O) The prediction of adult body measurements from measurements taken each year from birth to 5 years. Archives of Disease in Childhood, 31, 372.

Tanner, J. M., Whitehouse, R. H., and Healy, M. J. R. (1962). $A \rightarrow$ New System for Estimating Skeletal Ma.urity from the Hand and $\Theta$ Wrist, with Standards Derived from a Study of 2,600 Healthy $\mathrm{v}$ British Children. Parts 1 and II. Centre International de l'Enfance, Paris.

Tanner, J. M., Whitehouse, R. H., Hughes, P. C. R., and Vince, F. P. 음 (1971). The effect of human growth hormone treatment for 1 to 7 years on growth of 100 children, with growth hormone deficiency, low birthweight, inherited smallness, Turner's syndrome and other complaints. Archives of Disease in Childhood, 46, 745.

Tanner, J. M., Whitehouse, R. H., Marshall, W. A., Healy, M. J. R., and Goldstein, H. (1975). Assessment of Skeletal Maturity and Prediction of Adult Height: TW2 Method. Academic Press, New York.

Tanner, J. M., Whitehouse, R. H., Marubini, E., and Resele, L. (1976). The adolescent growth spurt of the boys and girls of the Harpenden Growth Study. Annals of Human Biology. (In the press.)

Tanner, J. M., Whitehouse, R. H., and Takaishi, M. (1966). Standards from birth to maturity for height, weight, height $\delta$ velocity, and weight velocity, British children 1965. Archives of 3 Disease in Childhood, 41, 454.

Walker, R. N. (1974). Standards for somatotyping children: I. Prediction of young adult height from children's growth data. Annals of Human Biology, 1, 149.

Weiner. J. S., and Lourie, J. A. (1967). Human biology: a guide to field methods. International Biological Handbook No. 9 Blackwell Scientific Publications, Oxford.

Whitehouse, R. H., Tanner, J. M., and Healy, M. J. R. (1974). Diurnal variation in stature and sitting height in 12-14-year-old boys. Annals of Human Biology, 1, 103.

Correspondence to Professor J. M. Tanner, Department of Growth and Development, Institute of Child Health, 30 Guilford Street, London WC1N 1EH. 